\title{
Evaluation of effect of atorvastatin on left ventricular systolic function in rats with myocardial infarction via 2D-STI technique
}

\author{
YAN HUA $^{1 *}$, MANYING XIE $^{1 *}$, JIABAO YIN $^{1}$, YU WANG $^{1}$, LING GAN $^{1}$, MING SANG $^{2}$, \\ XIAODONG SUN ${ }^{2}$, MINGYANG LI ${ }^{3}$, SHANJUN LIU ${ }^{1}$ and JINZHI XU ${ }^{1}$ \\ ${ }^{1}$ Department of Ultrasound Imaging, ${ }^{2}$ Central Laboratory and ${ }^{3}$ Department of Cardiovascular Medicine, \\ Xiangyang No. 1 People's Hospital, Hubei University of Medicine, Xiangyang, Hubei 441000, P.R. China
}

Received October 16, 2017; Accepted February 14, 2018

DOI: $10.3892 /$ etm.2018.5951

\begin{abstract}
This report aims to evaluate the effect of atorvastatin (Ator) on left ventricular systolic function in myocardial infarction (MI) rats. Forty healthy adult Sprague-Dawley rats were randomly divided into four groups: Ator group, MI group, sham-operation group and normal group. The left anterior descending coronary arteries were ligated to establish the MI model; after modeling, the Ator group was treated with Ator for 4 consecutive weeks. The echocardiographic detection was performed; the left ventricular myocardial systolic peak velocities, strain and strain rates were analyzed using the 2D-STI technique. After 4 weeks, myocardial tissues were taken from all rats and received the pathological examination. Left ventricular end-diastolic diameter (LVEDD) and left ventricular end-systolic diameter (LVESD) in Ator group and MI group were increased after operation, but left ventricular ejection fraction (LVEF) and left ventricular fractional shortening (LVFS) were decreased; myocardial function were decreased significantly $(\mathrm{p}<0.05)$. After Ator treatment, myocardial function at the 3rd and 4th week after operation increased significantly $(\mathrm{p}<0.05)$. After Ator treatment, LVEDD and LVESD decreased while LVEF and LVFS increased in Ator group at the 3rd and 4th week after operation compared with MI group $(\mathrm{p}<0.05)$. At the 4 th week after operation, LVEDD and LVESD in Ator group were decreased compared with those at the 1st and 2nd week after operation, but LVEF and LVFS were increased compared with those at the 1 st , 2nd and 3rd week after operation $(\mathrm{p}<0.05)$. Pathological examination showed that necrosis and fibrosis of myocardial cells and inflammatory reaction were obvious
\end{abstract}

Correspondence to: Dr Jiabao Yin, Department of Ultrasound Imaging, Xiangyang No. 1 People's Hospital, Hubei University of Medicine, 15 Jiefang Road, Xiangyang, Hubei 441000, P.R. China E-mail: yin_jiabao1@163.com

*Contributed equally

Key words: two-dimensional speckle tracking imaging, left ventricular function, atorvastatin, myocardial infarction in MI group. The inflammatory reaction of myocardial cells and myocardial fibrosis were lighter in Ator group. Ator can effectively improve the left ventricular systolic function in MI rats, which could be related to the reduction of response to inflammation and fibrosis.

\section{Introduction}

Myocardial infarction (MI) refers to the myocardial necrosis caused by the serious and persistent acute myocardial ischemia based on the coronary artery disease, whose high morbidity and mortality rates have made it one of the important causes for the death of patients with cardiovascular disease. After MI, myocardial cell loss and cardiac remodeling lead to the impaired cardiac function, seriously affecting the life quality of patients, so the timely and effective treatment is particularly important. The statin drug is one of the commonly-used drugs in the clinical treatment of MI $(1,2)$. Preventive effect of atorvastatin on ventricular remodeling post myocardial infarction has been demonstrated by Reichert et al, Martin et al and Tang et al (3-5). In recent years, some scholars have found that statins can not only regulate the lipids, but also have the effects of anti-inflammation, anti-oxidative stress, inhibiting cell proliferation and alleviating cardiac remodeling after the application in treatment of MI (6-10). We used of two-dimensional speckle tracking imaging (2D-STI) to investigate the effects of atorvastatin on left ventricular systolic function. 2D-STI technology is a new technology developed in recent years to evaluate myocardial function, especially cardiac systolic and diastolic function under pathological conditions. This study aimed to evaluate the effect of atorvastatin (Ator) on left ventricular systolic function in MI rats using the two-dimensional speckle tracking imaging (2D-STI) technique.

\section{Materials and methods}

Experimental materials

Experimental subjects. Forty clean-grade healthy adult male Sprague-Dawley (SD) rats at the same age weighing 200-300 g with an average of $261.92 \pm 18.81 \mathrm{~g}$ were selected from the Experimental Animal Center of Hubei University of Medicine [animal production license: SCXK (Hubei) 2016-0008; 


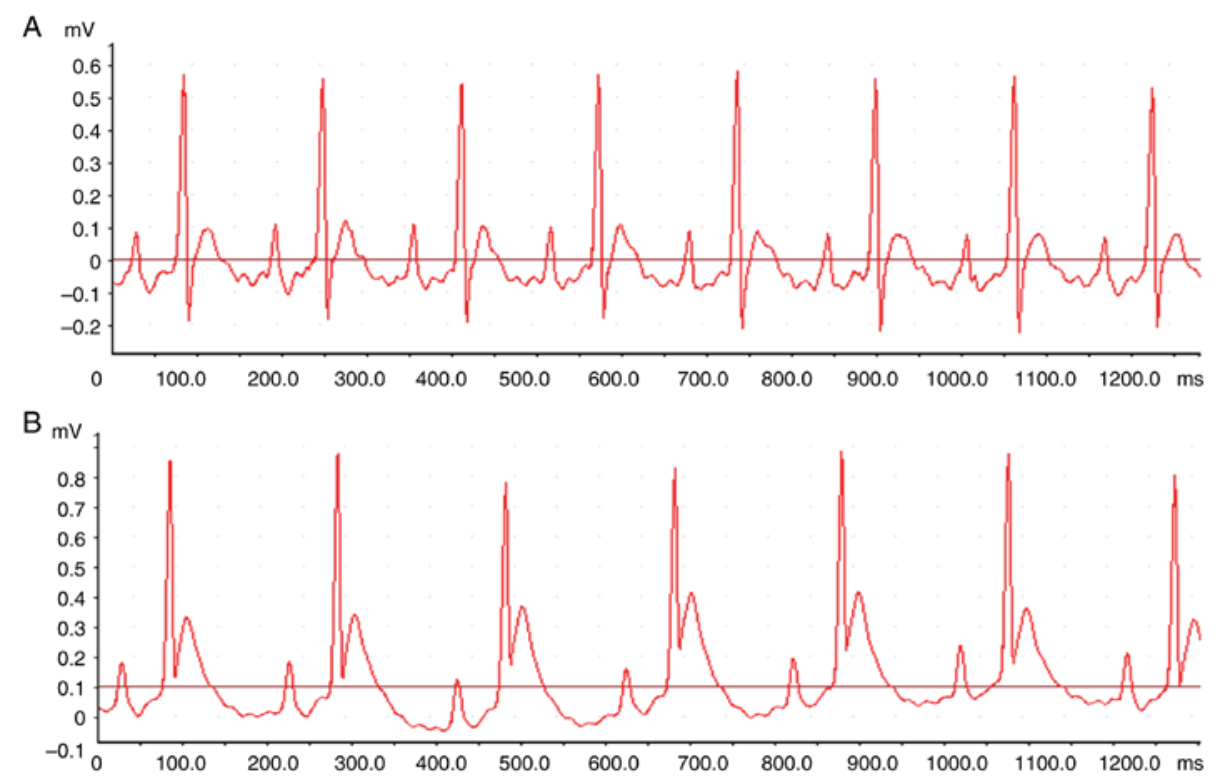

Figure 1. Changes in ECG before and after LAD ligation. (A) ECG before ligation. (B) ECG after ligation. ECG, electrocardiogram; LAD, left anterior descending.

animal use license: SYXK (Hubei) 2016-0031]. The animal experimental program was approved by the Ethics Committee of Xiangyang No. 1 People's Hospital, Hubei University of Medicine (Xiangyang, China); the disposal of animal in the experimental process conformed to the Guidelines on the Ethical Treatment of Animal issued by the Ministry of Science and Technology, People's Republic of China in 2006.

Instruments and reagents. Mindray Resona 7S color Doppler ultrasound diagnostic instrument (L14-5WU probe; Mindray Bio-Medical Electronics Co., Ltd., Shenzhen, China); TomTec 2D-STI analysis software (TomTec Imaging Systems GmbH, Unterschleissheim, Germany), small animal ventilator (RWD Life Technology Co., Ltd., Shenzhen, China); electrocardiogram (ECG) machine with BL-420 bio-signal collection system (Chengdu Techman Technology Co., Ltd., Chengdu, China); 10\% chloral hydrate (prepared by Xiangyang No. 1 People's Hospital, Hubei University of Medicine); H\&E dye liquor (Nanjing Jiancheng Biological Engineering Institute); Ator calcium tablets (trade name: Lipitor, Pfizer Pharmaceutical Co., Ltd.).

\section{Experimental methods}

Experimental grouping and drug treatment. Forty rats, in accordance with the random number table, were randomly divided into 4 groups with 10 rats in each group. In Ator group, left anterior descending coronary artery (LAD) was ligated to establish the MI model; after $24 \mathrm{~h}$, Ator was administrated $(10 \mathrm{mg} / \mathrm{kg} /$ day $)$ intragastrically for 4 weeks after being dissolved in normal saline. In MI group, at $24 \mathrm{~h}$ after establishment of MI model, the same amount of normal saline was administrated intragastrically for 4 weeks. In sham-operation group, LAD was looped with string, but not ligated. The normal group received no treatment.

Establishment of MI model (11)

Preoperative preparation. The rats were numbered, weighed, anesthetized with intraperitoneal injection of $10 \%$ chloral hydrate $(3 \mathrm{ml} / \mathrm{kg})$, and fixed under the supine position, followed by skin preparation and conventional disinfection. Connect the BL-420 bio-signal acquisition system to monitor the ECG. The catheter was inserted on the cervical trachea and connected with respirator.

$L A D$ ligation. After the breath was stable, a $2 \mathrm{~cm}$-long longitudinal incision was made on the 3rd-4th intercostal space in left chest, the subcutaneous fascia and each layer of muscle were separated, and the chest was opened. The pericardium was gently torn to show the LAD accompanying veins at the junction of pulmonary arterial cone and left aurcle. LAD was ligated with 6-0 swaged needle from 2-3 mm below the left aurcle and the left side of LAD accompanying veins; the needle was withdrawn near the interventricular groove.

Chest closure. After the successful ligation, the hematocele and foreign body in chest cavity were cleared, and the chest was closed coated with erythromycin ointment. After the spontaneous breathing was restored, the tracheal catheter was removed.

Signs of successful modeling. After the LAD ligation, the pale myocardium was visible in the blood supplying area in the distal ligated vessels, and the myocardial movement was weakened; in ECG, the persistent ST-segment elevation (Fig. 1) could be seen for at least $30 \mathrm{~min}$.

Modeling in sham-operation group. The myocardium around the LAD was looped with 6-0 swaged needle, but not ligated; other operation steps were the same as above.

Cardiac ultrasound image acquisition and analysis in rats Cardiac ultrasound images. Cardiac ultrasound images were collected from rats in Ator group, MI group and sham-operation group before and after operation once per week for 4 weeks. Rats in normal group received the cardiac ultrasonography once per week for 5 weeks.

Cardiac ultrasound detection methods. Rats were anesthetized, and fixed under the supine position, followed by skin preparation; ECG was recorded simultaneously; left 
A

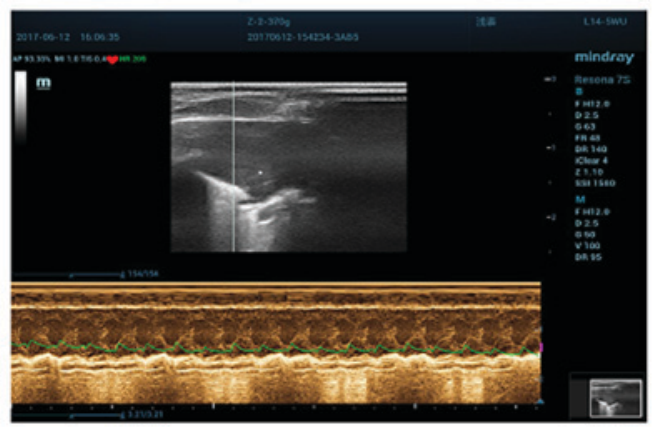

C

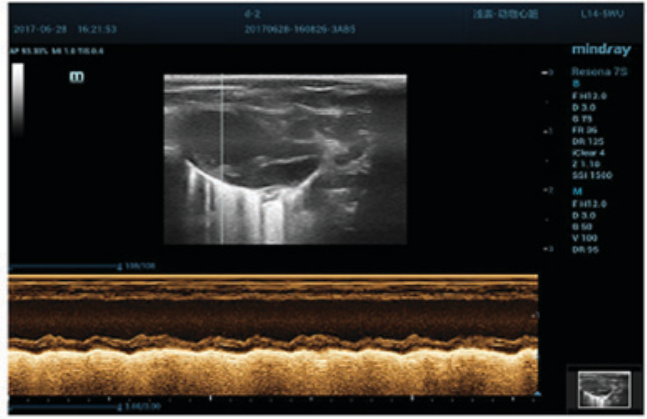

B

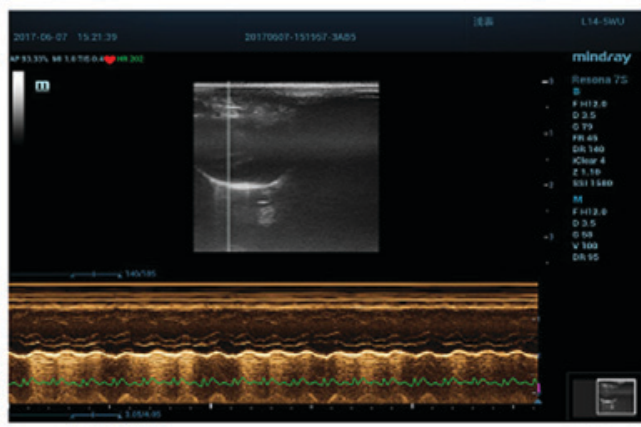

D

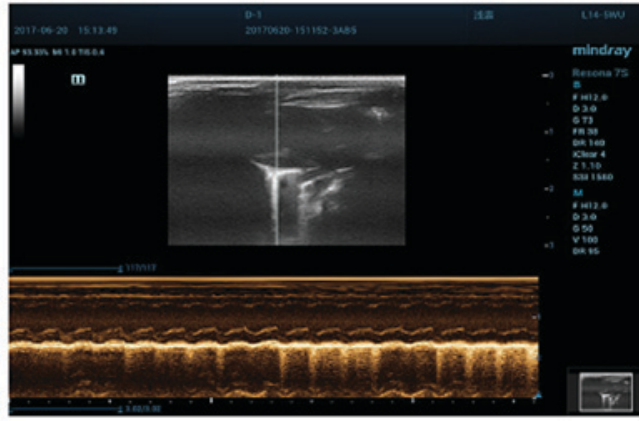

Figure 2. M-mode echocardiogram of the four groups. (A) Normal group. (B) Sham-operation group. (C) MI group. (D) Ator group.

A

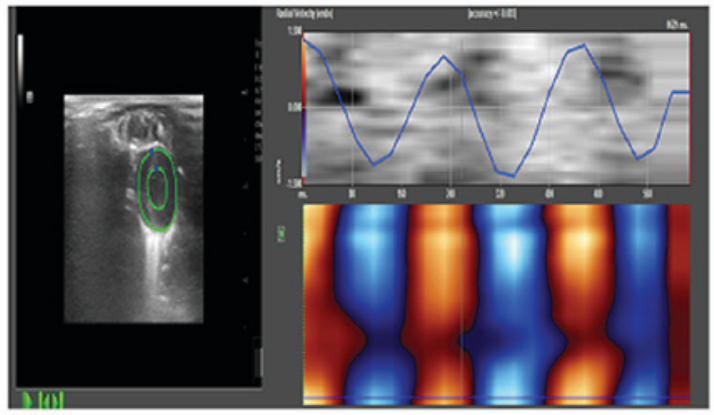

\section{C}

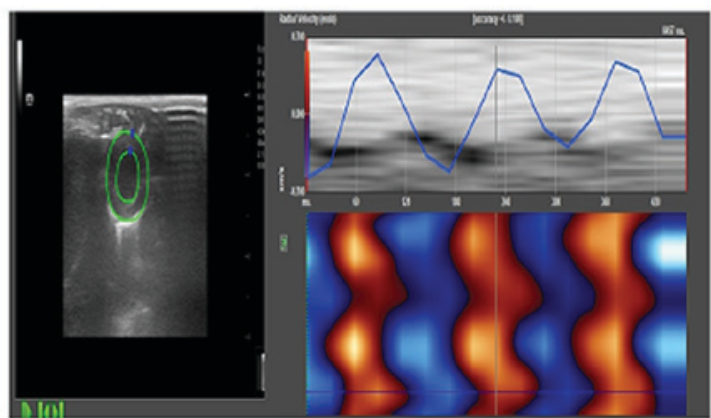

B
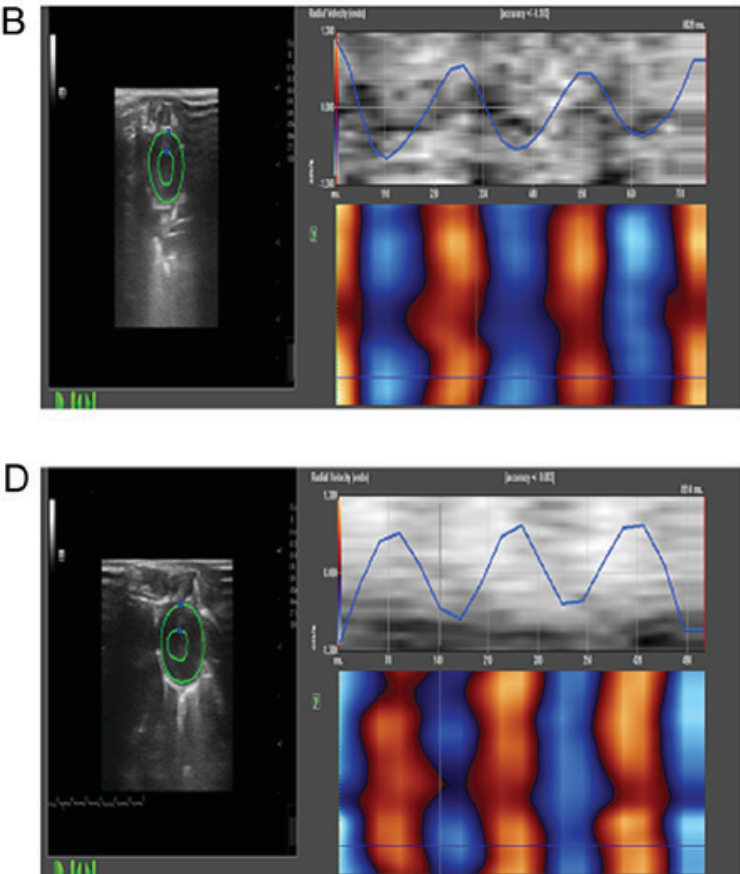

Figure 3. Images of radial velocities of anterior wall at the left ventricular short-axis papillary muscle level in the four groups. (A) Normal group. (B) Shamoperation group. (C) MI group. (D) Ator group.

ventricular end-diastolic diameter (LVEDD), left ventricular end-systolic diameter (LVESD), left ventricular ejection fraction (LVEF) and left ventricular fractional shortening (LVFS) were measured via the M-mode ultrasound images using the L14-5WU probe (Fig. 2). All indexes were measured for 3 times and the averages were taken.

Two-dimensional dynamic images. The two-dimensional dynamic images of at least three consecutive intact cardiac cycles were collected and stored at the views of parasternal left ventricle short axis papillary muscles and left ventricular short axis cardiac apex, left ventricular long axis view, apical two-chamber view, and apical four-chamber view, and analyzed off-line using the TomTec software. The clearest one-frame image of left ventricular endocardium was frozen, the left ventricular endometrial surface was checked manually, after automatically tracking the changes in myocardial motion; the tracking of endocardium curve in the entire cardiac cycle was adjusted. The radial, circumferential and longitudinal 
Table I. Echocardiogram measurement results of the four groups (mean $\pm \mathrm{SD}$ ).

\begin{tabular}{|c|c|c|c|c|}
\hline Group & LVEDD (cm) & $\operatorname{LVESD}(\mathrm{cm})$ & LVEF (\%) & LVFS (\%) \\
\hline \multicolumn{5}{|l|}{ Normal group } \\
\hline Preoperation & $0.59 \pm 0.06$ & $0.33 \pm 0.05$ & $84.58 \pm 5.09$ & $51.06 \pm 5.30$ \\
\hline The 1st week & $0.61 \pm 0.06$ & $0.35 \pm 0.05$ & $83.39 \pm 4.30$ & $50.55 \pm 6.27$ \\
\hline The 2nd week & $0.59 \pm 0.02$ & $0.36 \pm 0.06$ & $84.61 \pm 5.09$ & $51.59 \pm 5.38$ \\
\hline The 3rd week & $0.59 \pm 0.04$ & $0.34 \pm 0.05$ & $83.42 \pm 5.15$ & $51.40 \pm 4.60$ \\
\hline The 4th week & $0.60 \pm 0.05$ & $0.33 \pm 0.06$ & $84.52 \pm 5.07$ & $50.67 \pm 5.23$ \\
\hline \multicolumn{5}{|c|}{ Sham-operation group } \\
\hline Preoperation & $0.60 \pm 0.06$ & $0.34 \pm 0.05$ & $79.60 \pm 6.90$ & $53.54 \pm 4.94$ \\
\hline The 1st week & $0.62 \pm 0.06$ & $0.39 \pm 0.06$ & $78.96 \pm 8.60$ & $53.70 \pm 4.74$ \\
\hline The 2nd week & $0.63 \pm 0.06$ & $0.40 \pm 0.06$ & $80.08 \pm 7.50$ & $54.21 \pm 5.23$ \\
\hline The 3rd week & $0.65 \pm 0.06$ & $0.38 \pm 0.05$ & $78.65 \pm 8.15$ & $55.15 \pm 4.81$ \\
\hline The 4th week & $0.60 \pm 0.07$ & $0.35 \pm 0.07$ & $78.84 \pm 7.48$ & $54.54 \pm 4.94$ \\
\hline \multicolumn{5}{|l|}{ MI group } \\
\hline Preoperation & $0.60 \pm 0.08$ & $0.36 \pm 0.06$ & $81.49 \pm 8.46$ & $52.03 \pm 4.02$ \\
\hline The 1st week & $0.85 \pm 0.15^{\mathrm{a}-\mathrm{c}}$ & $0.56 \pm 0.10^{\mathrm{a}-\mathrm{c}}$ & $55.68 \pm 9.86^{\mathrm{a}-\mathrm{c}}$ & $39.47 \pm 6.07^{\mathrm{a}-\mathrm{c}}$ \\
\hline The 2nd week & $0.98 \pm 0.15^{\mathrm{a}-\mathrm{c}}$ & $0.62 \pm 0.09^{\mathrm{a}-\mathrm{c}}$ & $51.00 \pm 7.18^{\mathrm{a}-\mathrm{c}}$ & $32.97 \pm 4.03^{\mathrm{a}-\mathrm{c}}$ \\
\hline The 3rd week & $1.04 \pm 0.13^{\mathrm{a}, \mathrm{c}}$ & $0.69 \pm 0.10^{\mathrm{a}, \mathrm{c}}$ & $45.81 \pm 4.82^{\mathrm{a}, \mathrm{c}}$ & $27.74 \pm 5.20^{\mathrm{a}, \mathrm{c}}$ \\
\hline The 4th week & $1.16 \pm 0.14^{\mathrm{a}, \mathrm{c}}$ & $0.77 \pm 0.16^{\mathrm{a}, \mathrm{c}}$ & $42.93 \pm 4.42^{\mathrm{a}, \mathrm{c}}$ & $23.19 \pm 4.91^{\mathrm{a}, \mathrm{c}}$ \\
\hline \multicolumn{5}{|l|}{ Ator group } \\
\hline Preoperation & $0.66 \pm 0.07$ & $0.39 \pm 0.08$ & $81.34 \pm 8.33$ & $53.06 \pm 4.60$ \\
\hline The 1st week & $0.93 \pm 0.13^{\mathrm{a}-\mathrm{c}}$ & $0.76 \pm 0.15^{\mathrm{a}-\mathrm{c}}$ & $51.80 \pm 6.97^{\mathrm{a}-\mathrm{c}}$ & $36.08 \pm 4.12^{\mathrm{a}-\mathrm{c}}$ \\
\hline The 2nd week & $0.98 \pm 0.10^{\mathrm{a}-\mathrm{c}}$ & $0.78 \pm 0.13^{\mathrm{a}-\mathrm{c}}$ & $56.15 \pm 8.61^{\mathrm{a}-\mathrm{c}}$ & $36.14 \pm 5.19^{\mathrm{a}-\mathrm{c}}$ \\
\hline The 3rd week & $0.86 \pm 0.07^{\mathrm{a}, \mathrm{c}, \mathrm{d}}$ & $0.62 \pm 0.10^{\mathrm{a}, \mathrm{c}, \mathrm{d}}$ & $64.06 \pm 7.64^{a-d}$ & $43.31 \pm 4.21^{\mathrm{a}-\mathrm{d}}$ \\
\hline The 4th week & $0.78 \pm 0.07^{\mathrm{a}, \mathrm{c}, \mathrm{d}}$ & $0.52 \pm 0.10^{\mathrm{a}, \mathrm{c}, \mathrm{d}}$ & $73.19 \pm 5.68^{\mathrm{a}, \mathrm{d}}$ & $48.44 \pm 3.58^{\mathrm{a}, \mathrm{d}}$ \\
\hline
\end{tabular}

${ }^{a}$ In the comparison within the same group before and after operation, $\mathrm{p}<0.05$; ${ }^{\text {in }}$ the comparison at the 4 th week after operation with that at the 1st, $2 \mathrm{nd}$ and $3 \mathrm{rd}$ weeks after operation, $\mathrm{p}<0.05$; 'in the comparison between MI group/Ator group and normal group/sham-operation group at the same time-points after operation, $\mathrm{p}<0.05$; din the comparison between Ator group and MI group at the same time-points after operation, $\mathrm{p}<0.05$.

myocardial systolic peak velocities, strain and strain rates of left ventricular anterior, lateral, posterior, inferior, anteroseptal, posteroseptal walls and apex were obtained (Fig. 3). All the analysis and measurement were performed by two ultrasound doctors in a double-blind way, and the average was taken.

Pathological examination. After 4 weeks, all rats were euthanized; the hearts were taken out, and washed in the precooled normal saline to remove the blood and connective tissues outside the heart, followed by fixation in $10 \%$ neutral formalin, paraffin embedding, section cutting, hematoxylin-eosin (H\&E) staining, and observation under the light microscope (x400).

Statistical analysis. SPSS 17.0 software (SPSS, Inc., Chicago, IL, USA) was used for statistical analysis. Measurement data were presented as mean \pm standard deviation (mean $\pm \mathrm{SD}$ ). The one-way analysis of variance (ANOVA) was used for the within-group comparison at different time, while the repeated measures ANOVA was used for the between-group comparison at the same time. $\mathrm{p}<0.05$ suggested that the difference was statistically significant.

\section{Results}

Survival of $S D$ rats. During the experiment, 7 rats died. Finally, 10 rats were enrolled into the normal group, 9 rats into the sham-operation group, 7 rats into the MI group and 7 rats into the Ator group.

Comparisons of conventional ultrasound measurement results (Table I and Fig. 4)

Within-group comparisons at different time-points. LVEDD and LVESD in Ator group and MI group were increased after operation, but LVEF and LVFS were decreased. The differences were statistically significant $(\mathrm{p}<0.05)$. After Ator treatment, LVEDD and LVESD in Ator group were decreased at the 4th week after operation compared with those at the 1st and 2nd week after operation, but LVEF and LVFS in Ator group were increased compared with those at the 1st, 2nd and 3rd week after operation. The differences were statistically significant $(\mathrm{p}<0.05)$. At the 4th week, LVEDD and LVESD in MI group were increased, but LVEF and LVFS were decreased after operation compared with those at the 1st and 2nd week after operation. The differences were statistically significant 

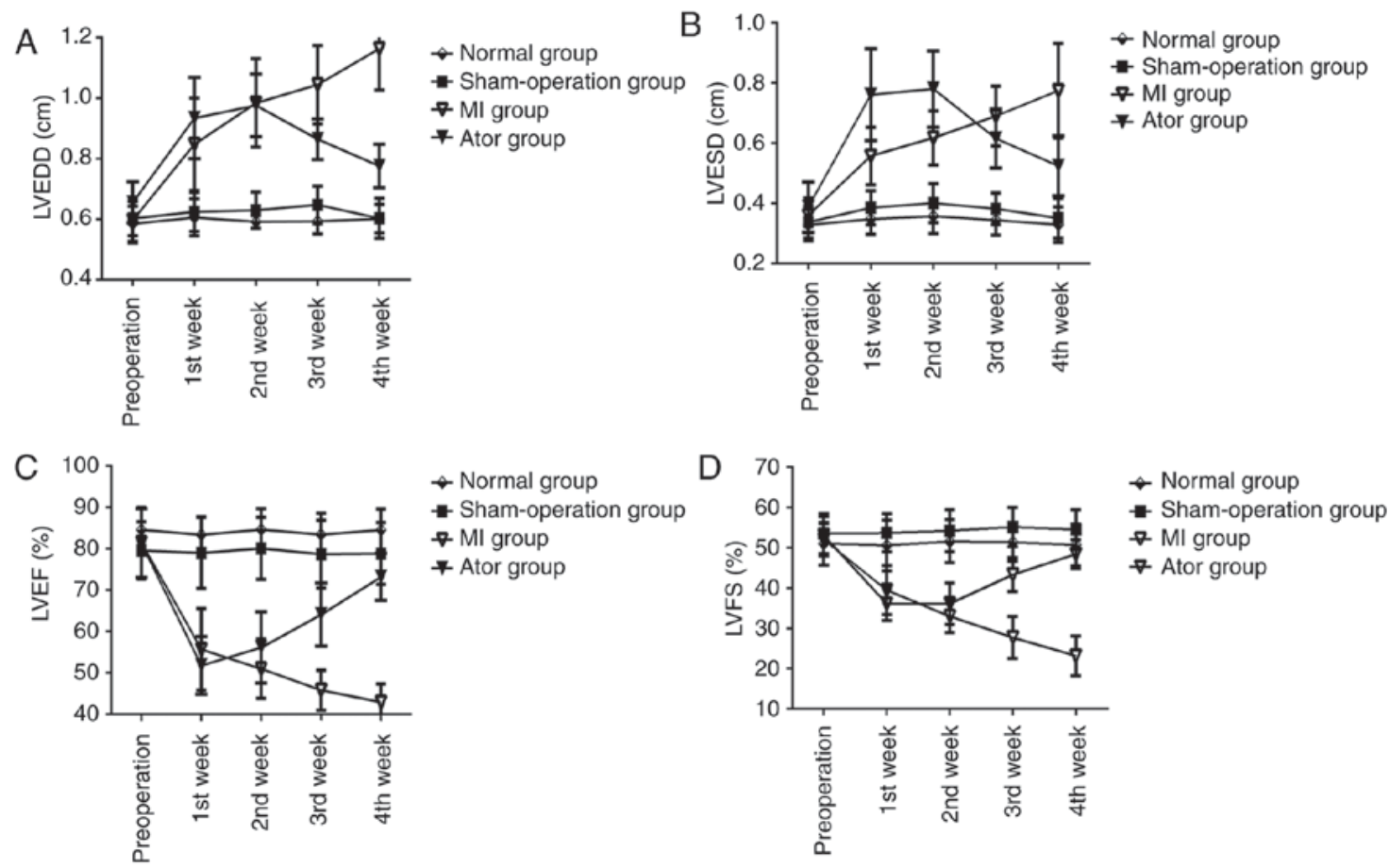

Figure 4. Echocardiogram measurement results of the four groups. (A) LVEDD. (B) LVESD. (C) LVEF. (D) LVFS.
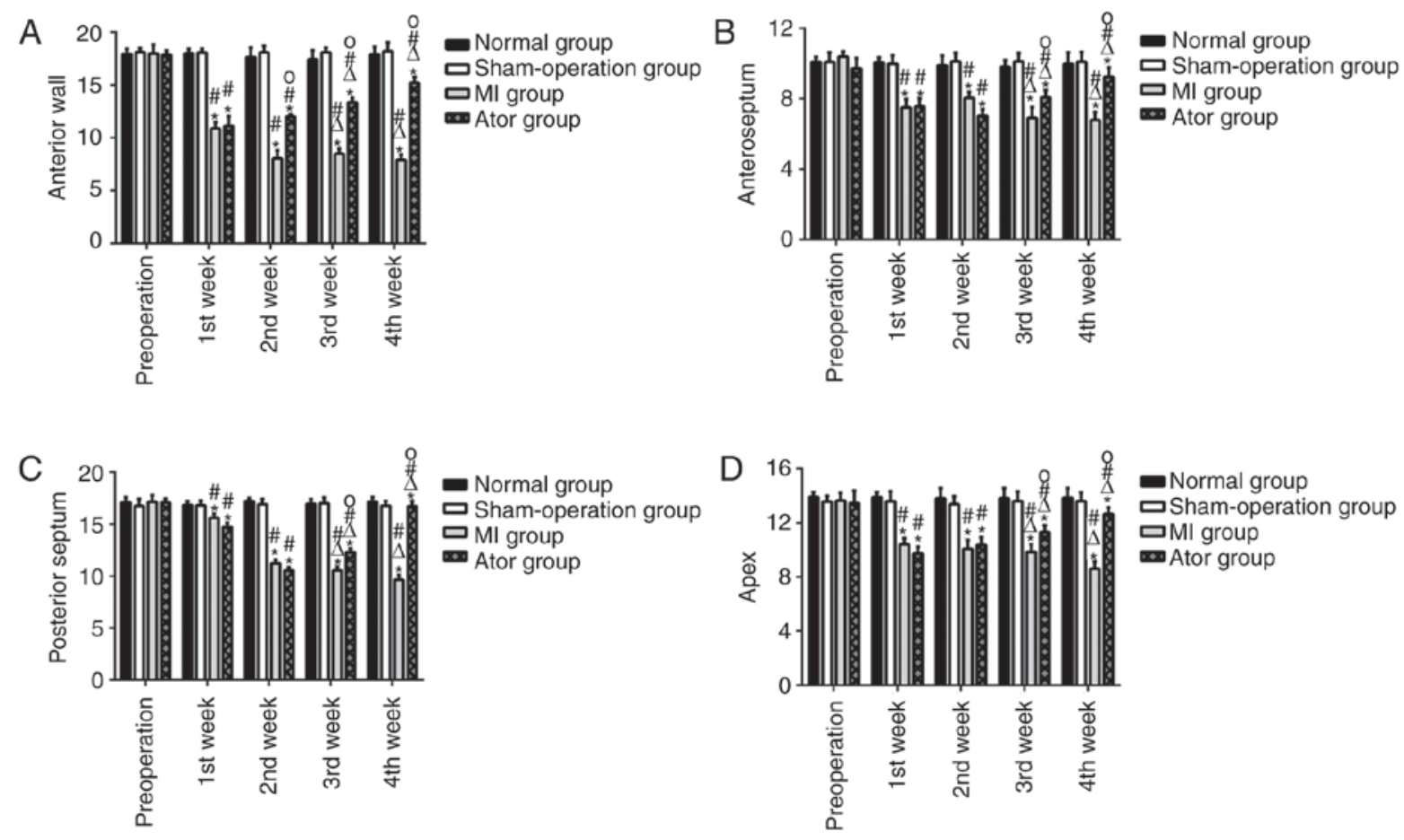

Figure 5. Radial strain values of four left ventricular segments of the four groups. (A) Anterior wall. (B) Anteroseptal wall. (C) Posteroseptal wall. (D) Apex. ${ }^{*} \mathrm{p}<0.05$, in the comparison within the same group before and after operation; ${ }^{*} \mathrm{p}<0.05$, in the comparison at the 3rd and 4th weeks after operation with that at the 1 st and 2 nd weeks after operation; ${ }^{\circ} \mathrm{p}<0.05$, in the comparison with normal and sham-operation group at the same time-points; ${ }^{\Delta} \mathrm{p}<0.05$, in the comparison with MI group at the same time-points.

$(\mathrm{p}<0.05)$. There were no statistically significant differences in conventional ultrasound indexes between normal group and sham-operation group before and after operation ( $p>0.05)$.

Between-group comparisons at the same time-points. Compared with those in normal group and sham-operation group at the corresponding time-points, LVEDD and LVESD in Ator group and MI group were increased, but LVEF and LVFS were decreased $(\mathrm{p}<0.05)$. After Ator treatment, compared with those in MI group at the 3rd and 4th week after operation, LVEDD and LVESD in Ator group were decreased, but LVEF and LVFS were increased. The differences were statistically significant $(p<0.05)$. There were no statistically 
Table II. Comparisons of radial strain of seven left ventricular segments of the four groups (mean \pm SD).

\begin{tabular}{|c|c|c|c|c|c|c|c|}
\hline Group & $\begin{array}{l}\text { Anterior } \\
\text { wall }\end{array}$ & $\begin{array}{c}\text { Lateral } \\
\text { wall }\end{array}$ & $\begin{array}{l}\text { Posterior } \\
\text { wall }\end{array}$ & $\begin{array}{l}\text { Inferior } \\
\text { wall }\end{array}$ & Anteroseptum & $\begin{array}{l}\text { Posterior } \\
\text { septum }\end{array}$ & Apex \\
\hline \multicolumn{8}{|l|}{ Normal group } \\
\hline Preoperation & $17.94 \pm 0.46$ & $20.46 \pm 1.15$ & $19.32 \pm 0.05$ & $8.50 \pm 0.59$ & $10.08 \pm 0.27$ & $17.11 \pm 0.49$ & $13.92 \pm 0.35$ \\
\hline The 1 st week & $18.01 \pm 0.40$ & $20.43 \pm 0.74$ & $19.32 \pm 0.06$ & $8.70 \pm 0.75$ & $10.06 \pm 0.27$ & $16.84 \pm 0.39$ & $13.89 \pm 0.39$ \\
\hline The 2nd week & $17.64 \pm 0.89$ & $20.43 \pm 0.48$ & $19.25 \pm 0.71$ & $8.31 \pm 0.84$ & $9.88 \pm 0.56$ & $17.20 \pm 0.31$ & $13.81 \pm 0.75$ \\
\hline The 3rd week & $17.43 \pm 0.85$ & $20.60 \pm 0.34$ & $19.54 \pm 0.50$ & $8.94 \pm 0.79$ & $9.80 \pm 0.38$ & $16.95 \pm 0.44$ & $13.82 \pm 0.74$ \\
\hline The 4 th week & $17.90 \pm 0.75$ & $20.50 \pm 0.42$ & $19.35 \pm 0.51$ & $8.39 \pm 1.11$ & $9.96 \pm 0.66$ & $17.17 \pm 0.44$ & $13.84 \pm 0.72$ \\
\hline \multicolumn{8}{|l|}{$\begin{array}{l}\text { Sham-operation } \\
\text { group }\end{array}$} \\
\hline Preoperation & $18.13 \pm 0.35$ & $20.58 \pm 0.48$ & $19.13 \pm 0.59$ & $8.23 \pm 0.63$ & $10.09 \pm 0.54$ & $16.76 \pm 0.66$ & $13.59 \pm 0.39$ \\
\hline The 1st week & $18.07 \pm 0.34$ & $20.37 \pm 0.60$ & $19.57 \pm 0.59$ & $8.51 \pm 1.08$ & $9.97 \pm 0.48$ & $16.80 \pm 0.47$ & $13.59 \pm 0.74$ \\
\hline The 2nd week & $18.10 \pm 0.63$ & $20.25 \pm 0.70$ & $19.53 \pm 0.64$ & $8.35 \pm 0.55$ & $10.12 \pm 0.48$ & $16.91 \pm 0.49$ & $13.37 \pm 0.59$ \\
\hline The 3rd week & $18.10 \pm 0.41$ & $20.38 \pm 0.44$ & $19.26 \pm 0.82$ & $8.31 \pm 1.04$ & $10.11 \pm 0.49$ & $17.00 \pm 0.56$ & $13.61 \pm 0.71$ \\
\hline The 4 th week & $18.21 \pm 0.83$ & $20.52 \pm 0.66$ & $19.06 \pm 0.49$ & $8.22 \pm 0.82$ & $10.09 \pm 0.56$ & $16.77 \pm 0.45$ & $13.61 \pm 0.65$ \\
\hline \multicolumn{8}{|l|}{ MI group } \\
\hline Preoperation & $17.98 \pm 0.84$ & $20.58 \pm 0.36$ & $19.42 \pm 0.62$ & $8.12 \pm 0.75$ & $10.39 \pm 0.29$ & $17.15 \pm 0.63$ & $13.65 \pm 0.69$ \\
\hline The 1st week & $10.90 \pm 0.60^{\mathrm{a}, \mathrm{c}}$ & $20.50 \pm 0.62$ & $9.06 \pm 0.64$ & $8.19 \pm 0.59$ & $7.50 \pm 0.48^{\mathrm{a}, \mathrm{c}}$ & $15.62 \pm 0.42^{\mathrm{a}, \mathrm{c}}$ & $10.42 \pm 0.44^{\mathrm{a}, \mathrm{c}}$ \\
\hline The 2nd week & $8.06 \pm 0.76^{\mathrm{a}, \mathrm{c}}$ & $20.12 \pm 0.83$ & $19.52 \pm 0.79$ & $8.23 \pm 0.71$ & $8.03 \pm 0.35^{\mathrm{a}, \mathrm{c}}$ & $11.22 \pm 0.35^{\mathrm{a}, \mathrm{c}}$ & $10.07 \pm 0.65^{\mathrm{a}, \mathrm{c}}$ \\
\hline The 3rd week & $8.50 \pm 0.48^{\mathrm{a}-\mathrm{c}}$ & $20.47 \pm 0.39$ & $19.40 \pm 0.76$ & $8.08 \pm 1.18$ & $6.90 \pm 0.61^{\mathrm{a}-\mathrm{c}}$ & $10.54 \pm 0.37^{\mathrm{a}-\mathrm{c}}$ & $9.85 \pm 0.61^{\mathrm{a}-\mathrm{c}}$ \\
\hline The 4 th week & $7.93 \pm 0.50^{\mathrm{a}-\mathrm{c}}$ & $20.47 \pm 0.59$ & $19.44 \pm 0.21$ & $8.10 \pm 0.91$ & $6.78 \pm 0.46^{\mathrm{a}-\mathrm{c}}$ & $9.64 \pm 0.47^{\mathrm{a}-\mathrm{c}}$ & $8.61 \pm 0.52^{\mathrm{a}-\mathrm{c}}$ \\
\hline \multicolumn{8}{|l|}{ Ator group } \\
\hline Preoperation & $17.86 \pm 0.40$ & $20.56 \pm 0.44$ & $19.13 \pm 0.46$ & $8.59 \pm 0.99$ & $9.71 \pm 0.58$ & $17.09 \pm 0.35$ & $13.46 \pm 0.91$ \\
\hline The 1st week & $11.12 \pm 0.92^{\mathrm{a}, \mathrm{c}}$ & $20.38 \pm 0.51$ & $19.01 \pm 0.59$ & $8.53 \pm 0.94$ & $7.56 \pm 0.46^{\mathrm{a}, \mathrm{c}}$ & $14.73 \pm 0.40^{\mathrm{a}, \mathrm{c}}$ & $9.72 \pm 0.49^{\mathrm{a}, \mathrm{c}}$ \\
\hline The 2nd week & $12.02 \pm 0.21^{\mathrm{a}, \mathrm{c}, \mathrm{d}}$ & $20.63 \pm 0.16$ & $19.04 \pm 0.57$ & $8.51 \pm 0.98$ & $7.02 \pm 0.38^{\mathrm{a}, \mathrm{c}}$ & $10.54 \pm 0.31^{\mathrm{a}, \mathrm{c}}$ & $10.37 \pm 0.56^{\mathrm{a}, \mathrm{c}}$ \\
\hline The 3 rd week & $13.35 \pm 0.42^{\mathrm{a}-\mathrm{d}}$ & $20.61 \pm 0.45$ & $19.35 \pm 0.60$ & $8.28 \pm 1.02$ & $8.08 \pm 0.41^{\mathrm{a}-\mathrm{d}}$ & $12.27 \pm 0.38^{\mathrm{a}-\mathrm{d}}$ & $11.33 \pm 0.49^{\mathrm{a}-\mathrm{d}}$ \\
\hline The 4 th week & $15.20 \pm 0.55^{\mathrm{a}-\mathrm{d}}$ & $20.55 \pm 0.55$ & $19.14 \pm 0.82$ & $8.53 \pm 0.89$ & $9.23 \pm 0.53^{\mathrm{a}-\mathrm{d}}$ & $16.72 \pm 0.51^{\mathrm{a}-\mathrm{d}}$ & $12.64 \pm 0.48^{\mathrm{a}-\mathrm{d}}$ \\
\hline
\end{tabular}

${ }^{a}$ In the comparison within the same group before and after operation, $\mathrm{p}<0.05$; ${ }^{\text {bin }}$ the comparison at the 3 rd and 4 th weeks after operation with that at the 1 st and 2 nd weeks after operation, $\mathrm{p}<0.05$; cin the comparison with normal group and sham-operation group, $\mathrm{p}<0.05$; ${ }^{\mathrm{d}}$ in the comparison with MI group at the same time-points, $\mathrm{p}<0.05$.

significant differences in the conventional ultrasound indexes between normal group and sham-operation group at the same time-points $(\mathrm{p}>0.05)$.

Comparison of 2D-STI detection indexes (Table II and Fig. 5) Within-group comparisons at different time-points. The radial, circumferential and longitudinal myocardial systolic peak velocities, strain and strain rates of left ventricular anterior, anteroseptal, posteroseptal walls and apex in Ator group and MI group after operation were decreased significantly and the differences were statistically significant $(\mathrm{p}<0.05)$. The radial, circumferential and longitudinal myocardial systolic peak velocities, strain and strain rates of left ventricular lateral, posterior, inferior walls had no significant changes $(\mathrm{p}>0.05)$. At the 3rd and 4th week after operation, the radial, circumferential and longitudinal myocardial systolic peak velocities, strain and strain rates of left ventricular anterior, anteroseptal, posteroseptal walls and apex in Ator group were increased compared with those at the 1 st and 2 nd week after operation $(\mathrm{p}<0.05)$, while they were decreased in MI group compared with those at the 1 st and 2 nd week after operation $(\mathrm{p}<0.05)$. There were no statistically significant differences in the radial, circumferential and longitudinal myocardial systolic peak velocities, strain and strain rates in the 7 segments of left ventricular in normal group and sham-operation group after operation compared with those before operation ( $\mathrm{p}>0.05)$.

Between-group comparisons at the same time-points. Compared with those in normal group and sham-operation group at the 1st week after operation, the radial, circumferential and longitudinal myocardial systolic peak velocities, strain and strain rates of left ventricular anterior, anteroseptal, posteroseptal walls and apex in Ator group and MI group were decreased, and the differences were statistically significant $(\mathrm{p}<0.05)$; there were no statistically significant differences in the radial, circumferential and longitudinal myocardial systolic peak velocities, strain and strain rates of left ventricular anterior, anteroseptal, posteroseptal walls and apex at the 1st week after operation between MI group and Ator group ( $p>0.05)$, but at the 3rd and 4th week, there were significant increase and the differences were statistically significant $(\mathrm{p}<0.05)$. 
A

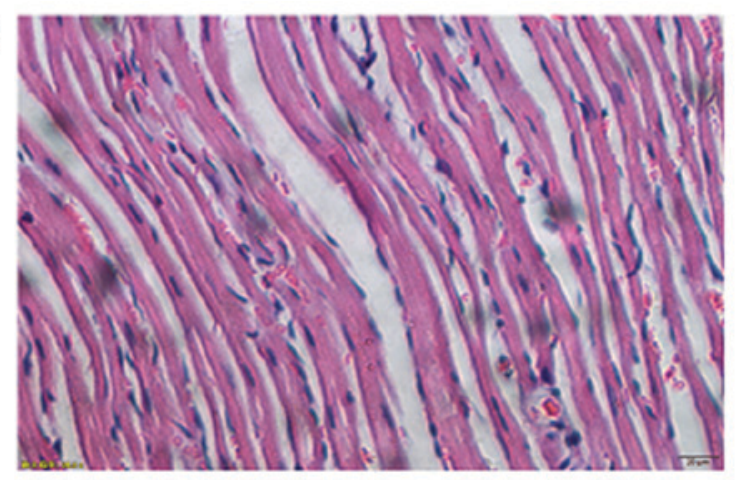

C

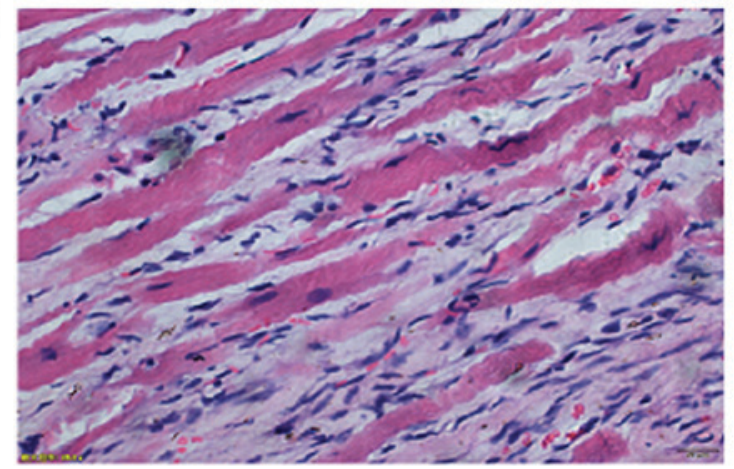

B

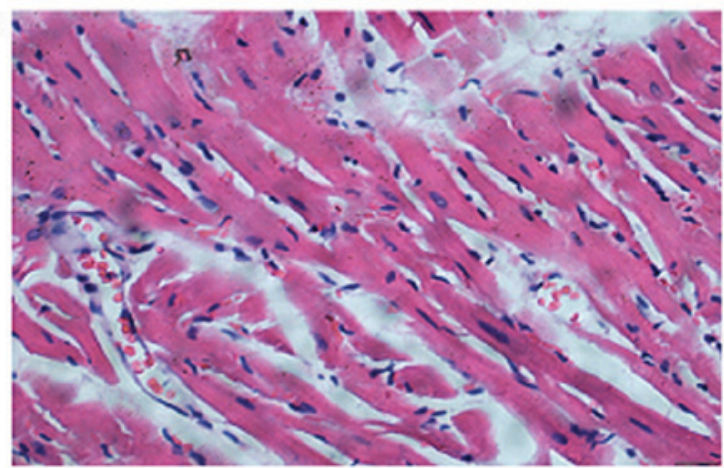

D

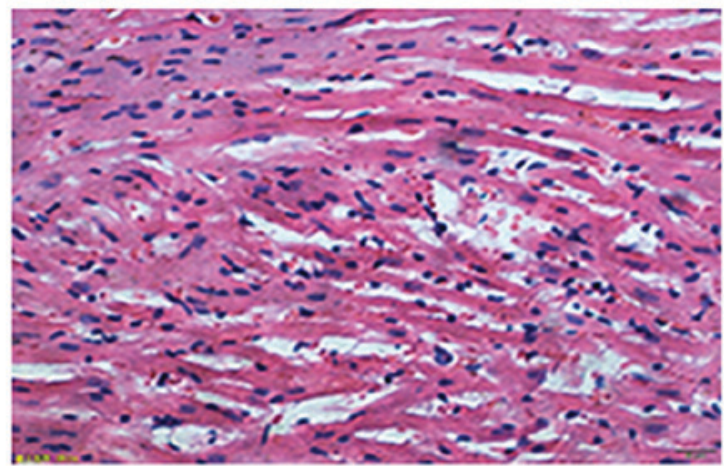

Figure 6. H\&E staining results of the four groups. (A) Normal group. (B) Sham-operation group. (C) MI group. (D) Ator group.

There were no statistically significant differences in the radial, circumferential and longitudinal myocardial systolic peak velocities, strain and strain rates of left ventricular lateral, posterior, inferior walls among the four groups before and after operation at corresponding time-points ( $\mathrm{p}>0.05)$.

Pathological examination results of left ventricular anterior myocardium. In normal group, the structure of myocardial cells were clear, tissues were arranged neatly and stained evenly, and there was no obvious inflammatory cell infiltration in intermuscular space. In sham-operation group, the structure of myocardial cells was arranged less neatly, and there were a few necrotic myocardium and fibrous hyperplasia. In MI group, there were massive ischemic necrosis of myocardial cells, fibrosis in some areas and fracture of partial muscle fibers in the few remaining cardiac fibers; massive inflammatory cell infiltration could be seen in intermuscular space. In Ator group, there were a few necrotic myocardium cells and fibrotic areas; a little inflammatory cell infiltration still could be seen in intermuscular space (Fig. 6).

\section{Discussion}

After MI, inflammation, myocardial loss, cardiac remodeling and other factors lead to the weakened myocardial motion and decrease the cardiac function; the accurate assessment of myocardial motor function is of great significance in evaluating the degree of myocardial injury, choosing the therapeutic regimen and assessing the treatment effect.

Myocardial motion can be divided into the longitudinal, radial and circumferential motion $(12,13)$. 2D-STI technique can automatically identify and track the spatial motion of acoustic spots of myocardial tissues in the region of interest frame by frame. Moreover, it can qualitatively and quantitatively describe the movement speed, strain, strain rate and rotation angle of myocardial tissues in the three motor directions; this technique is not obviously angle-dependent and not susceptible to the surrounding tissues and myocardium. It is accurate, rapid and sensitive when assessing the myocardial movement and deformation, so in recent years it has become a newly-developed technique to evaluate the myocardial function, especially the cardiac systolic and diastolic functions in the pathological state $(14,15)$.

Among the drugs commonly-used in the treatment of MI, the statin drug is a kind of 3-hydroxy-3-methyl glutaryl coenzyme A (HMG-COA) reductase inhibitor that can competitively inhibit the activity of rate-limiting enzyme HMG reductase during cholesterol synthesis, inhibit the cholesterol synthesis, and reduce the low-density lipoprotein (LDL) level (16). After applied to MI, the statin drug can prevent the secondary myocardial infarction and other cardiovascular events by regulating blood lipid levels.

In this study, Ator was administered to MI rats for 4 weeks; the left ventricular myocardial systolic motion was monitored using the 2D-STI technique, and the myocardial pathological changes were observed via H\&E staining. The results showed that after Ator treatment, LVEDD and LVESD were decreased at the 3rd and 4th week after operation compared with MI group at the same time-points, while LVEF and LVFS were increased; LVEDD and LVESD were decreased at the 4th week compared with those at the 1st and 2 nd week after operation, while LVEF and LVFS were increased compared with those at the 1st, 2nd and 3rd week after operation. The differences were statistically significant $(p<0.05)$, which 
meant the M-mode echocardiogram detection index were improved significantly. It showed that Ator can improve left ventricular systolic function in MI rats. Besides, the anterior, anteroseptal, posteroseptal walls and apex which were LAD blood supplying area, radial, circumferential and longitudinal systolic peak velocities, strains, and strain rates were increased significantly at the 3 rd and 4th week after operation compared with those at the 1st and 2nd week after operation and those in MI group at the same time, which was further proved that Ator can effectively improve the left ventricular systolic function in MI rats. Its mechanism may be related with that Ator can significantly reduce the level of C-reactive protein (CRP) and serum amyloid protein A (17), promote the neutrophil apoptosis (18), reduce the inflammatory response, reduce the depletion of glutathione peroxidase (GSH-Px) and superoxide dismutase (SOD) (19), resist the oxidative stress and protect cells. Furthermore, myocardial tissues H\&E staining showed that the inflammatory response of myocardial tissues and fibroplasia was alleviated after Ator treatment, further proving that Ator can alleviate myocardial inflammatory response and myocardial fibrosis.

In this experiment, MI rats were used as the objects of study, and the improvement of cardiac function was observed using the single medication mode, which eliminated the effect of confounding factors in clinical combined medication therapy of coronary heart disease on the evaluation of drug therapeutic effect. At the same time, the accurate and sensitive 2D-STI technique improved the reliability of the experimental result. However, there were also some limitations in this experiment: i) the dose of Ator used in this experiment was $10 \mathrm{mg} / \mathrm{kg} / \mathrm{day}$, and the dose was single, so the drug concentration gradient needs to be increased to explore the appropriate concentration and side effects of Ator; ii) Ator is the lipid-lowering drug, but the objects of this study were the healthy SD rats, so whether the effect of statin drugs on cardiac function will be affected remain unknown yet if the observed objects have dyslipidemia; iii) the mechanism of Ator in improving the left ventricular systolic function after MI remains to be further investigated.

\section{Acknowledgements}

Not applicable.

\section{Funding}

No funding was received.

\section{Availability of data and materials}

The datasets used and/or analyzed during the present study are available from the corresponding author on reasonable request.

\section{Authors' contributions}

YH, MX, JY and MS participated in the design of the experiments. YH, MX and ML performed the experiments. YW, SL and JX extracted the data. MX, YH and LG analyzed the data. YH, MX prepared the initial draft, and MX, YH, JY and XS prepared the final manuscript. All authors read and approved the final manuscript.

\section{Ethics approval and consent to participate}

The animal experimental program was approved by the Ethics Committee of Xiangyang No. 1 People's Hospital, Hubei University of Medicine (Xiangyang, China).

\section{Consent for publication}

Not applicable.

\section{Competing interests}

The authors declare that they have no competing interests.

\section{References}

1. Lai HM, Aronow WS, Mercando AD, Kalen P, Desai HD, Gandhi K, Sharma M, Amin H and Lai TM: The impact of statin therapy on long-term cardiovascular outcomes in an outpatient cardiology practice. Med Sci Monit 17: CR683-CR686, 2011.

2. Xiao X, Chang G, Liu J, Sun G, Liu L, Qin S and Zhang D: Simvastatin ameliorates ventricular remodeling via the TGF- $\beta 1$ signaling pathway in rats following myocardial infarction. Mol Med Rep 13: 5093-5101, 2016.

3. Reichert K, Pereira do Carmo HR, Galluce Torina A, Diógenes de Carvalho D, Carvalho Sposito A, de Souza Vilarinho KA, da Mota Silveira-Filho L, Martins de Oliveira PP and Petrucci O: Atorvastatin improves ventricular remodeling after myocardial infarction by interfering with collagen metabolism. PLoS One 11: e0166845, 2016.

4. Martin JH, Connelly KA, Boyle A, Kompa A, Zhang Y, Kelly D, Gilbert RE and Krum H: Effect of atorvastatin on cardiac remodelling and mortality in rats following hyperglycemia and myocardial infarction. Int J Cardiol 143: 353-360, 2010.

5. Tang XL, Sanganalmath SK, Sato H, Bi Q, Hunt G, Vincent RJ, Peng Y, Shirk G, Dawn B and Bolli R: Atorvastatin therapy during the peri-infarct period attenuates left ventricular dysfunction and remodeling after myocardial infarction. PLoS One 6: e25320, 2011.

6. Mihaylova B, Emberson J, Blackwell L, Keech A, Simes J, Barnes EH, Voysey M, Gray A, Collins R and Baigent C; Cholesterol Treatment Trialists' (CTT) Collaborators: The effects of lowering LDL cholesterol with statin therapy in people at low risk of vascular disease: Meta-analysis of individual data from 27 randomised trials. Lancet 380: 581-590, 2012.

7. Song T, Liu J, Tao X and Deng JG: Protection effect of atorvastatin in cerebral ischemia-reperfusion injury rats by blocking the mitochondrial permeability transition pore. Genet Mol Res 13: 10632-10642, 2014.

8. Whitehead NP, Kim MJ, Bible KL, Adams ME and Froehner SC: A new therapeutic effect of simvastatin revealed by functional improvement in muscular dystrophy. Proc Natl Acad Sci USA 112: 12864-12869, 2015.

9. Lee J, Hong EM, Jang JA, Park SW, Koh DH, Choi MH, Jang HJ and Kae SH: Simvastatin induces apoptosis and suppresses insulin-like growth factor 1 receptor in bile duct cancer cells. Gut Liver 10: 310-317, 2016.

10. Neukamm A, Høiseth AD, Einvik G, Lehmann S, Hagve TA, Søyseth V and Omland T: Rosuvastatin treatment in stable chronic obstructive pulmonary disease (RODEO): A randomized controlled trial. J Intern Med 278: 59-67, 2015.

11. Wang M, Li Z, Zhang X, Xie X, Zhang Y, Wang X and Hou Y: Rosuvastatin attenuates atrial structural remodelling in rats with myocardial infarction through the inhibition of the p38 MAPK signalling pathway. Heart Lung Circ 24: 386-394, 2015.

12. Waldman LK, Nosan D, Villarreal F and Covell JW: Relation between transmural deformation and local myofiber direction in canine left ventricle. Circ Res 63: 550-562, 1988.

13. Li L, Craft M, Hsu HH, Zhang M, Klas B, Danford DA and Kutty S: Left ventricular rotational and twist mechanics in the human fetal heart. J Am Soc Echocardiogr 30: 773-780, e1, 2017. 
14. Amundsen BH, Helle-Valle T, Edvardsen T, Torp H, Crosby J, Lyseggen E, Støylen A, Ihlen H, Lima JA, Smiseth OA, et al: Noninvasive myocardial strain measurement by speckle tracking echocardiography: Validation against sonomicrometry and tagged magnetic resonance imaging. J Am Coll Cardiol 47: 789-793, 2006.

15. Aurich M, Keller M, Greiner S, Steen H, Aus dem Siepen F, Riffel J, Katus HA, Buss SJ and Mereles D: Left ventricular mechanics assessed by two-dimensional echocardiography and cardiac magnetic resonance imaging: Comparison of highresolution speckle tracking and feature tracking. Eur Heart $\mathbf{J}$ Cardiovasc Imaging 17: 1370-1378, 2016.

16. Sirtori CR: The pharmacology of statins. Pharmacol Res 88 : 3-11, 2014.

17. Kinlay S, Schwartz GG, Olsson AG, Rifai N, Leslie SJ, Sasiela WJ, Szarek M, Libby P and Ganz P; Myocardial ischemia reduction with aggressive cholesterol lowering study investigators: High-dose atorvastatin enhances the decline in inflammatory markers in patients with acute coronary syndromes in the MIRACL study. Circulation 108: 1560-1566, 2003.
18. Mandal P, Chalmers JD, Graham C, Harley C, Sidhu MK, Doherty C, Govan JW, Sethi T, Davidson DJ, Rossi AG, et al: Atorvastatin as a stable treatment in bronchiectasis: A randomised controlled trial. Lancet Respir Med 2: 455-463, 2014.

19. Nazli Y, Colak N, Alpay MF, Uysal S, Uzunlar AK and Cakir O: Neuroprotective effect of atorvastatin in spinal cord ischemiareperfusion injury. Clinics (Sao Paulo) 70: 52-60, 2015.

This work is licensed under a Creative Commons Attribution-NonCommercial-NoDerivatives 4.0 International (CC BY-NC-ND 4.0) License. 